\title{
The Controversial Portrayal of Women in Persian Proverbs
}

\author{
Seyyed Naser Jaberi Ardakani ${ }^{1}$, Hossein Aliakbari Harehdasht ${ }^{1} \&$ Leila Hajjari ${ }^{1}$ \\ ${ }^{1}$ Persian Gulf University of Bushehr, Iran \\ Correspondence: Leila Hajjari, M.A., English Language and Literature, Persian Gulf University of Bushehr, Iran. \\ E-mail: lhajjari@gmail.com
}

Received: April 30, $2015 \quad$ Accepted: May 25, $2015 \quad$ Online Published: August 31, 2015
doi:10.5539/ells.v5n3p146
URL: http://dx.doi.org/10.5539/ells.v5n3p146

\begin{abstract}
In the recent years, lots of varied studies have been conducted to investigate the conditions of women in Iran. The main provocative in them among other things was to defy the traditional ideologies that deemed women inferior. One of the places which have been very effective and mostly ignored by the scholars was the Persian proverbs, the cornucopia of varied ideologies for or against women. Our aim is, therefore, to demonstrate the problems that the study of women in the Persian proverbs cause for the scholars and reveal the contradictions which make any judgment impossible. As there are innumerable proverbs about women in Iran, mostly originating from the Persian literature, prose or poetry, we have decided to concentrate on some of the main roles of women as reflected in the proverbs. We hope that the study of the existing contradictions or oppositions in the portrayal of women in Persian proverbs will provide objective results to help other scholars further the studies on and about women in similar areas.
\end{abstract}

Keywords: Persian proverbs, women, roles, contradiction

\section{Introduction}

Women have been interesting subjects of study commented on and argued about in innumerable different ways in our time. Part of such studies concerns the role of women in the classical texts: legends, anecdotes and tales, religious, mythological, or fictional. The researchers investigate these texts in order to find out the ideas about women in their ancient or modern societies. Nonetheless, one of the means by which they could study women was the proverbs. The Persian proverbs have been very influential on the mind of the people, common or elite. If a statement is accepted in society, it means that it has an almost irrefutable quality. Persian literary texts are replete with proverbs that people use today, the proverbs which mirror how the people, male or female, in the past or present, were observed and judged. What makes this study interesting is its focus on the controversial quality of these proverbs concerning women, the quality which has made the study of women in Persian proverbs both interesting and unintelligible. In this study, therefore, the proverbs focalizing women have been the main objective because very few critics have studied them from this point of view. We will look for some evidence in the proverbs to reveal the ways women are represented in them and in doing so, whenever possible, we will show the contradiction inherent in the proverbs.

\section{Literature Review}

There are some very interesting works which have been inspiring to the authors of this paper, the works which address women in Persian literature. Some more specifically deal with proverbs focalizing women and their beauty, social roles, passion, inferiority, or even their holiness. As an example, Mohammadpour et al. (2012) in "An Elaborate Study of Women in Kurdish Proverbs" portray Kurdish women as taking varied roles such as irrational beings, forces against men, inferior to men, or elevated as holy and divine creatures (pp. 65-83). Movahhed et al. (2012) in their "A Sociological Study of Women in the Proverbs of Lamerd in Fars Province" have traced the Lamerdi women and have noticed that women are restricted to the household dominated by patriarchy serving their men (pp. 101-120). Mohammad Ali Borhani Shahrestani in Women Mirrored in the Proverbs (2006) has just gathered the proverbs about women without any analytic evaluation of them. Jalal Sattari, in his The Portrait of a Woman in Iranian Culture (2009), has portrayed the role and position of the Iranian women in the history and literature of Iran. Although the book has little to say about the Iranian proverbs, it has been very helpful in other, especially literary, respects. There are other related studies as follows: "Another Look at a Woman's Status in Persian Literature; Pondering on Nizami's and Ferdowsi's Narration of the Story of 
Khosro and Shirin" (Davari, 2005, pp. 277-308). The author of this article believes that Ferdosi has not given an important role to Shirin whereas Nizami has placed her as the foundation of the story. Thus he believes that the Khosro and Shirin that we know today are Nizami's creation. "Woman and the Fall; How False Beliefs about Women Flourished in Some Persian Literary Texts" (Sajjadi et al., 2008, pp. 161-186) is an interesting article wherein there is an attempt by the authors to prove that the beliefs which deem a lowly position to women compared to men originate from the mythic beliefs popular in ancient Mesopotamia as well as from the agnostic belief of the second century A.D. in Rome; they took the man as a symbol for the sky and the Spirit whereas the woman represented the earth, the former celestial and divine and the latter terrestrial and base.

\section{The Problems Causing Difficulty for the Present Research}

Because proverbs have public use which eventually indicates their autonomous acceptability in the society, the polemic examination of the Persian proverbs have almost been ignored and few have decided to challenge the ideas that are commonly shared by the majority of the people. The scientific study of the proverbs, however, encounters technological hindrances as well. There is no searchable database (software) for the Persian proverbs. If there were one, the research on and about the proverbs would be much easier. Due to this shortage, we had to read through Dehkhoda's Amsal and Hikam and through The Encyclopedia of Persian Proverbs as well as some other secondary sources page by page. Thererfore, we had to spend much more time than needed to get the samples. Besides, nearly all the sources for conducting the study are in Persian. As in this study, the authors who wish to write a research paper on women based on their portrayal in the Persian proverbs has to study everything in Persian and then translate all into English for international publications. In fact, all our sources listed in the references were in Persian and we have translated all the proverbs and quotations from the secondary sources into English.

The next important problem lies in the fact that the proverbs and their meanings, forms, and usage, are subject to change in the course of time. The bases of the compilation by the authors of the dictionaries or encyclopedias were different; for instance, Dehkhoda has concentrated on classical and literary proverbs and has brought lots of examples from poetry. Zolfaghari, however, has brought examples from prose texts which are of common use, practical, and folkloric. Which of these two approaches can include more proverbs is in itself a very important point to be taken into consideration. It is believed that the recent generation has less interest and eventually less use for the proverbs which come from poetry and literary texts compared to the older generations. Due to the change of time and the people's taste, the more up-to-date and the more practical the proverbs are, the more aligned with human nature, or at least, the more popular they become and attain more public use. This makes the choice of the proverbs and the sources for research in the field very difficult. In this research, the proverbs that appear in the known sources (whether Amsal and Hikam or The Encyclopedia of Persian Proverbs) are the ones that the authors attempt to study. Since there is a unanimous trust in the putative sources that authors use for their research, They have skipped the study of such issues as whether they are still used or not, or if they belong to all levels of the society or they were used by small groups of elites. Thus, they have tried to use both poetry and prose proverbs out of necessity.

\section{Generalizing Proverbs}

There are various generalizing proverbs about women. In fact, the philosophical naturalism and holistic expressions about women's nature are common in literature and philosophy. The main difference between the two and the view of our contemporaries lies in their way of expression; philosophers and poets of the past had more openly criticized women for the weaknesses that they believed all women possessed. They often used satiric and sardonic expressions to refer to the weaknesses which were considered as women's natural quality. On the contrary, psychology in general or personality psychology specifically avoids generalization and natural determinism of both literature and philosophy.

\subsection{Women and Deceitfulness}

One of the general qualities of women is their deceitfulness. This and some other qualities regarding women's beguiling character appear in the proverbs without any proof:

What is a woman but a mark to wile / in truth at war, in aspect peace awhile? (Nizami, 1999, p. 369)

"A woman who can deceive another woman is the goddess of deception" (Zolfaghari, 2009, p. 1144)

\subsection{Women and Irrationality}

Some proverbs emphasize women's weakness in reasoninng: "A woman lacks reason (the English equivalent is the ironic "a woman's reason" see $O E D$ ), "a woman's reason is on her lap, when she gets up, it falls," "A woman is a button short, or a rib short" [meaning that she is short of understanding or reason] (Zolfaghari, 2000, p. 
1144). The idea that women are weaker than men in their ability to reason is a cliché in patriarchal societies.

One must also take into consideration the fact that women have also been dubious about men's rationality. Therefore, it is natural to find different means of measurement to evaluate these two sexes and their wisdom because each weighs the amount of the rationality of the other in his/her own scale. There are instances, however, when power of reasoning is investigated not in its abstract sense, but rather in its practical and professional meaning. In this case, it equals the ability to do a certain job or accomplish a task. Today, some psychologists believe that men are more skillful in doing certain scientific activities than women. For example, they believe that men are better in mathematics [or chess] which involve pure mental strength (Cohen, 2005, p. 142). This, if true (there is no universal consensus for the matter), because of the variety of the meaning of the word wisdom or rationality, cannot mean that women lack reasoning or power of mind. This can just indicate that the two sexes have different capabilities. There is yet the belief that women are much stronger in emotionality and acute in feelings accepted by many men as well as women. This ability to feel much more strongly has made their worldview different from that of men. Probably, it is due to the acceptance of women's emotionality that the second phase of feminist critics has stopped seeking the equality of men and women concerning "reason" and the ability to rationalize; they seek to concentrate on their sensibility as the source of their superiority, and believe that the unending problems of the world today have been the result of men's arid rationality (Mardiha, 2005, pp. 7-10). Scientifically speaking, the claims against women's lack of rationality are groundless and hard to prove. Thus, below, we will concentrate on the proverbs which are less radical and will skip those which are biased.

\subsection{Women as Mystery}

Some proverbs are about unknowability of women. This is because it is not easy to know women folks. This is, in fact, because mankind in general is unknowable. The difference between men and women is the root of this unknowability because men want to define women in terms of their known criteria. Despite the many problems that are caused by the differences between them, these differences are the true reason why they are attracted to one another. In the Persian proverbs, there are some references to the unknowability of women which signify the patriarchal nature of these proverbs and men's little knowledge of the fair sex. The credibility of these proverbs is hard to repudiate and they are as old as the Persian history. Some good examples appear in the following proverbs: "It is impossible to know a woman," (Zolfaghari, 2010, p. 1139) or "A woman is like an unsliced watermelon," and "Women are all snow white, their sane ones are hard to say from the insane ones, crows are all pitch black, their old ones are hard to say" (Zolfaghari, 2010, p. 1142).

\subsection{Women and Power}

The proverbs that delineate women's hidden influence over the strongest men and their empowering force on men are used by many people indicating the general consensus concerning the claims in those proverbs. As Rumi asserts, a woman is love and a desire that causes motion, unrest, and sacrifice in the lover. The effect is very strong and despite the accepted superiority of men over women in the traditional and patriarchal societies, men are ready to walk on foot and enjoy seeing their beloveds ride on their horses, hence the proverb: "Women ride whereas men follow on foot" (Zolfaghari, 2010, p. 1142). This can also be indicative of the fact that women are the leaders and men follow whether out of love or out of need; a woman is sometimes teased for her ill-power: "If a woman is kept with a dog in a large woolen sack, it's unkindness to the dog" (Zolfaghari, 2010, p. 1139). Although the proverb has a negative tone in it, it is still a sign of a woman's unbending strength and unyielding determination. If through macho power she gains a total dominance over a man, her sovereignty is given voice in the form of a derogatory term Saliteh (سليطل or shrew, henpecking), which is a derogatory inflection of the word Sultan (سلطان or king). The term Saliteh or shrew is used when a woman is completely dominant over her man and through commanding and governing she has left no place for him to govern the family affairs. There are some Persian proverbs that tease this kind of dominance because it is unnatural in the traditional structure of the Persian society: "A shrew, henpecking woman is like an unleashed dog. She is the husband to her man" (Dehkhoda, 2011, p. 1356). Despite the fact that there are few proverbs that testify the supremacy of the woman in the house as in "A woman is the boss at home" (Zolfaghari, 2010, p. 1139), the people in the past were against her dominance, "Tis better to have no beard to see it a bridle in a woman's hand" (Dehkhoda, 2011, p. 606), and it is still partly the case in Iranian modern society.

He who obeys his wife

has husbanded, not a wife has taken

But will such a man listen at all

Good words he has from his ears shaken (Anvari, 2010, p. 505) 


\subsection{Women, Tongue, Secrets and Eavesdropping}

"A woman does not let the pea wet in her mouth" (Zolfaghari, 2010, p. 1143) which means "a woman conceals what she knows not," that is, she is unable to keep secrets, also indicates that she talks incessantly, especially about trivial subjects.

It is a truth universally acknowledged that men are better trustees and keep secrets whereas women unleash them quickly. Men are inclined to believe that women are bad confidantes and secrets very quickly slip out of their mouths. Will Durant has a teasing statement about it. He says, "According to Franklin, a secret may remain untold when two of the three women who know it die, but to prove this there should be a large number of dead men and women" (2010, p. 139). There are plenty of Persian proverbs either in the form of prose or poetry about women's inability to keep secrets:

"Telling secrets to women is in vain

Thou shalt soon find it in the lane

'Tis unworthy of honorable gentlemen

To share their secrets with women" (Ferdowsi, 1997, p. 218)

Despite its relative truth, one might say that women's inability to keep secrets is the product of the patriarchal culture and language. Men and women differ in the degree of their considering a piece of information a secret; it is also probable that women's inclination towards intimacy and building up relationships through narration makes secretive action or speech insignificant. Who knows how much knowledge they have gained through gathering around and sharing their personal experiences which would remain in men's hidden boxes of unmentionables. Women in their intimacy share very personal information which would be out of question among men; they share things that would remain as secrets in the hearts of men. Psychologists believe that women follow a certain model of friendship and intimacy in which revealing what is private becomes inevitable. As Rice argues the common model of male friendship is based on having a lot of friends with little or no knowledge of the other's private life (1999, p. 392). The fact that women, unlike men, speak about everything in their intimacy has made men think that women are unable to keep secrets. This is one of the reasons for the existing gaps between men and women which is inevitable but understandable. We must not forget that women's revelatory relationship is induced by their need for a listening companion as well as their different perspective to things around them.

\subsection{Women and Their Interest in Ornament and Charm}

In the Persian proverbs, women are portrayed as very much interested in ornament and charm which is a universal phenomenon. In some Persian proverbs, this interest has been criticized which might be because of some women's extravagant love of jewelry and gold. Some believe that the love of luxury and adornment in the house are feminine. This feminine quality has been used to criticize men as well:

Women seek as adornment silver and gold / Men wisdom and action adornment called (Nasser Khosrow, 1999, p. 87)

A wife is a wife if loyal not adorned / A head is a head if wise not crowned (Sanayee, 2011, p. 536)

\section{Contradiction}

An important problem that one faces in the study of the proverbs, also the main concern here, is the contradictory nature of the proverbs. As an instance, there are controversial opinions about beating a woman, or cheat on her, or even about the superiority of the male child over the female.

There is a proverb that says: "never beat a woman even with a flower stick" (Zolfaghari, 2010, p. 1139). Another goes: "To be beaten is to be a woman (Note 1)" (p. 1144). Regarding loyalty to one's wife, in one proverb we read, "When married, do not covet another's wife / If you do you shall find yourself in strife" (O'hadi, 1908, p. 89). In another proverb, it says: "To kiss one's own wife is to bark up the wrong tree" (Dehkhoda, 2001, p. 1354). Regarding a child's sex, despite the fact that most people prefer a son to a daughter, in the following proverb the difference has been noted to be insignificant:

A child if disciplined and polite / A girl and a boy both delight (Ferdowsi, 1997, p. 90)

Contradictions in the proverbs have many different reasons and indicate that proverbs have many different types of use in life. Since life is replete with ups and downs and moments of contradictions, the same is true for the proverbs. In the above examples about beating or respecting a woman, the first proverb has a moral lesson whereas the second indicates human desire for power. It is quite natural for moral advice to oppose and to prohibit human desire and eventually to contradict it. Such examples show that the study of the proverbs needs 
lots of attention to minute nuances of semantics and syntax.

\subsection{Women: High and Low Roles to Play}

The word, woman (j) in Persian is a distinctive term that differentiates between men and women depending on

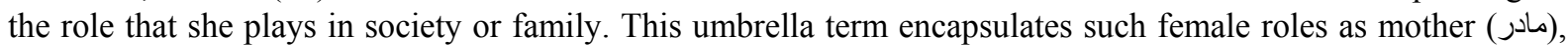

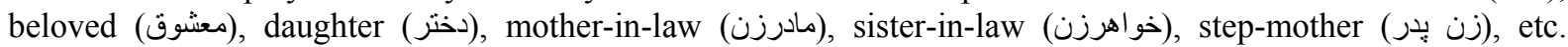
Therefore, it is very important to note the perspective from which each of these roles is evaluated and/or judged.

The term, mother, is mostly positive in the Iranian culture and one cannot find a nation-wide accepted proverb in which she is censured even though there are very few poems or proverbs which praise her. All that has been said about the value of a mother appears in tales and stories demonstrating the positive qualities of women in general.

The term, woman, in the Persian language is also associated, as went before, with some other words such as mother-in-law (مادرزن) or step-mother (زن بـر) which are not positive; they have negative connotations, (it is interesting to note that the word mother in these negative combinations do not appear in the Persian classical literature or philosophy except for some sparse appearance in oral literature, folklore anecdotes, and proverbs).

A woman as a man's beloved, however, has been the subject of admiration with limitless resonance in both Persian poetry and prose, finding its way to the proverbs as well. This last issue has paradoxically caused both praise and worry because in the lyrical poetry of the Persian classical literature the beautiful girl is a goddess who is worshiped and in the prose tales and anecdotes she is the source of worry to her family because she is brought up to be married to a man as his lord.

It should be noted that women in general are not presented as positive in literature or in the proverbs. To determine the reason, we should first point to the roles in which women are negatively presented and name the faults for which they have been criticized in those texts. What role or which picture of the woman is portrayed in the proverbs or poems are the clues to the mechanisms of her inferiority.

This is not easy to say because of the dual treatment of women in the roles they have taken in society; however, we will demonstrate those roles and leave the judgment to our respected readers.

One of the main roles of women is women as wives. In this role, they are either the complement to their men and hence valued positively or a liability to them and to the whole family and thus depreciated. The following examples testify to the contradictory portrayal:

A bad woman in a good man's household

Is Hell to him in this very world

Leave a bad companion, go

O God keep us from inferno. (Saadi, 1995, p. 100)

In these examples, the word, woman, has been used to mean a wife. In the following examples, we see more instances of the relationship between a man as a husband and a woman as his wife:

“A woman is the man's vizier" (Zolfaghari, 2010, p. 1143). "A woman can turn a man into a man (مرد) or to a rascal (نامرد)" (Zolfaghari, 2010, p. 1143). "The man should hold the woman as the ashes holding the fire" (Zolfaghari, 2010, p. 1143), or "When a woman is ruined, her man knows first" (Zolfaghari, 2010, p. 1143). It is hard to say that in all the proverbs which the word woman has appeared it means solely the wife of a man, but all in all, it mainly stands for this usage of the word. When studying the proverbs, one can observe that the role of the woman as a wife is more recurrent than other roles ascribed to her testifying to the importance of this role among her other ones.

\subsection{Women's Deception with Words and Flattery}

Women are different from men in that they pay special attention to the kind of language used for/against them. Some poets (male oriented) consider women's infatuation with beautiful words and oily tongues as a weakness. As we read in Weis and Ramin, some lines have become proverbial (according to Amsal and Hikam).

Women trust what men kindly say

Their sweet words win their hearts away

Despite being percipient and clever

Their honey-tongued men they revere

They falter quickly when men say 
$\mathrm{O}^{\prime}$ lily in June, O' rose in May

If queens or princesses the women are

Or some chaste nuns in a convent far

They will fall for men's oily tongue

They don't seem to know the right from the wrong. (Gorgani, 1960, p. 54)

As these lines show, women adore being praised and are easily enchanted by flattery or sweet words. Regardless of what the manner of praise or intention behind the appraisal is, the truth is that they need it. Unlike women, men prefer not to be praised openly neither in their presence nor in their absence. The old more than the young, and women more than men, need praise and adoration. Those men who eschew the honest appraisal of their wives, have actually disregarded their women's natural needs and surely will pay for their neglect. It is because there is high probability that the women will seek sweetness in men other than their husbands (see Keinia, 1975, p. 26). Gray (2012) argues that despite their equal need for love and affection, men and women differ in the degree of it, and there is evidence that women clearly require more; their need for more love and affection is actually the main means of their feeling honorable and deserving. That is why men must notice their women very openly and regard them as very special and extraordinary (p. 350).

There are two opposite opinions about women's desire for praise and sweet words; one that considers it negative like what went in Gorgani's poem, and the one that deems it positive for being the woman's natural need requiring men to the strict sense of responsibility in order to fulfill this need for their wives. Surely men do not have the same skill for appraisal and certainly women differ in the amount of their pleasure; individual men should learn how to please their women. Moreover, in the existing tensions between some men and their wives, one cannot always blame the men for being less articulate. Rather, at times it is the woman who exceeds the limits of pleasure and becomes insatiable. The best remedy is the knowledge both couples should gain about their strength and weakness and act according to the golden mean of moderation.

\subsection{Women and Wealth}

Some of the Persian proverbs are about women's interest in gathering wealth: "A woman desires more than his man acquires" (Dehkhoda, 2011, p. 1356), "A woman reached a pile of salt, she filled in her underwear, too" (Zolfaghari, 2010, p. 1139).

How fairly said to Hushang the Zoroastrian priest

Neither shame nor manner is the dearest

To the woman pleased with more and more

Greed is her sphere, vanity her core. (Gorgani, 1970, p. 136)

As we see, the first example presents a general opinion about wanting more and can include every aspect of life, whether good or bad; however, the two other examples are indicative of women's greedy nature. This seems to be very hard to verify in the society because women in general have less wealth than men. The truth, nonetheless, is that not being wealthy does not imply lack of greed. Therefore, in order to speak with authority and authenticity about this matter, one should be able to determine the motivation behind men and women's gathering wealth, the motivation which must in some respect be different because of their difference in attitude.

We may look at the matter from this perspective that there might be some connection between men's desire for wealth and their desire to please their women. If true, then we must accept that the women's desire for more wealth - which is in turn motivated by their attention to the welfare of their families and children and originates from their foresightedness for the future - is identifiable by their ability to motivate their husbands for more wealth. Thus, they can be totally acquitted from the charge of being greedy or vain. Eventually, the proverbs that find faults with women are discredited. There are different researches in the field and the results are varied. For instance, the result of one research shows that women are willing to devote time to helping others whether in the form of giving financial or physical help (Simmons, 2007, p. 2014). Another research demonstrates that men have linked their judgment about the just world very seriously with money and finance (Golparvar, 2006, p. 58). The results of other researches show that women like saving money as a means of gathering wealth more than men do. This is probably due to the fact that it is women who manage the family affairs and are involved in and going in and out of different events (child birth, etc.) or think that they may live longer than their husbands and eventually should live alone at the old age. This is deemed as positive and educational. 


\section{Marriage as a Positive Phenomenon: Man and Woman as Complements}

Marriage is almost indispensable especially in Iran and celibacy has never been approved by the Iranians since ancient times. Whenever a youth reached a state of power and strength, all care was taken by the family to find a good wife for him. Girls had the same conditions and they were grown to be wed to an honorable man. A celibate young girl or boy was always a burden on the family. Some of the proverbs deal with the complementary roles of men and women. They show that each of the two sexes is dependent on the presence of the other one. Eventually, the success of one relies on the other's action. At times, a worthy wife can be the cause of an unworthy husband's worth: "The wife is the lining and her husband the coating. The wife is her husband's partner and his companion in hard times" (Zolfaghari, 2010, p. 1140). "The wife makes his man legendary" (p. 1142), "An able wife makes her failing husband worthy of success" (p. 1140),

Surely men heavily on their wives depend

Just as the ring holds its diamond

Good dough makes good bread

Happy men good wives have wed. (p. 1143)

A man's abilities have positive effects on his wife as well: "The breadwinner man of the house makes his wife a true lady" (p. 1142).

These positive proverbs justify marriages and in fact consider it necessary for both men and women because it is in their complementary union that each reaches his/her maximum ability.

\subsection{Women, Marriage, and the Characteristics of a Good Wife}

The proverbs that deem negative qualities as innate in women, despite their lack of validity, have been the basis of some of the researches on/about women. However, there are a lot of proverbs that concentrate on women as representing the ideal wife.

\subsubsection{The Maiden Worthy of an Espouse}

A major part of the proverbs are about the conditions that make a woman suitable for marriage. In these proverbs, the features of a worthy woman are not explained in detail; instead, some general qualities such as chastity, beauty and fertility, graceful clothing, and piety are their focal subjects. We will explain some of the major ones here:

\subsubsection{Chastity}

Chastity is defined as the "Exclusion of meretricious ornament; purity of style, modesty, chasteness," and the one who is chaste is "Morally pure, free from guilt, innocent" or "Decent; free from indecency or offensiveness" (The Oxford English Dictionary, 2009). In Iran, one of the main general qualities for a suitable wife is therefore chastity. A chaste woman's manner is also indicative of the fact that she is from a noble family. That is why, in the Iranian sayings or proverbs, there is much emphasis on marrying the chaste woman: "Even if ugly, marry the chaste woman; avoid the wanton one" (Dehkhoda, p. 1431). "It is easy to marry an unchaste woman, but difficult to live with her" (Dehkhoda, p. 1358).

\subsubsection{Pudency}

Pudency is not separable from chastity and the person who is chaste is eventually a pudent person as well. One cannot be chaste but impudent. A pudent woman is the one who has or shows "a sense of shame, esp. in regard to matters of a sexual nature; modest; delicate." (The Oxford English Dictionary, 2009). As we read in the proverbs or sayings, prose or poetry, pudency is one of the most important qualities that a woman should own to make her a good candidate for marriage. In Ferdowsi's Shahname (The Epic of the Persian Kings), a woman who lacks pudency suffers from a huge weakness. He has compared an unwise old man and a lazy youth with an impudent woman. He has named the three simultaneously because naturally wisdom is the quality of the old age, and activity that of youth, and pudency that of womanhood. As we read in Ferdowsi (1997),

Women folks, those who impudent are

Whose voice is loud and flies afar

Pure souls darken they in sooth

As do fond old men and lazy youths. (p. 205)

Pudency does not mean to be shy. It corresponds to all the good qualities that a well-bred noble woman owns. Such a woman is not shrill and speaks in a low voice; she has control over her desires and is not lecherous; she is 
well-mannered and loyal to her husband and to the demands of her family. These qualities are mostly earned through education and young girls learn them in their families. According to Will Durant (2010), In William James opinion, pudency is not innate but earned by labor: women have noticed that magnanimity (in sexual matters) ends in disgrace and humiliation, and they have taught it to their daughters (p. 129). Whatever the origin of pudency, in men's opinion, it is one of the main qualities of a good wife.

\subsubsection{Beauty and Fertility}

In some of the Persian proverbs, there are instances that disregard the woman's beauty as the determining quality for marriage. In fact, there is a dichotomy between the physical beauty and spiritual beauty and the proverbs prove that Iranians mostly opt for the latter. For example Maktabi asserts, "If a woman is chaste and kind / If not a beauty, don't mind" (qtd. in Amsal and Hikam, p. 1357). But even this proverb indicates that physical beauty cannot be totally ignored; the advice given by our ancient elders is just for lessening its significance for other more important qualities. In our time, physical beauty still matters. Atkinson et al. (2009) affirm that men all over the world, from Zambia to Austria, prefer women who are young and attractive (p. 626). Men, by choosing young and beautiful women as their wives, in fact, either knowingly or unknowingly, aim at having beautiful and strong children (Atkinson et al., p. 626; Barron et al., 2011, p. 472). Ferdowsi in other places in Shahname speaks about women's beauty positively, yet favors her wisdom:

A fair wife gives thee peace of mind

Watching her one shalt comfort find

But if good council a wise dame gives

The man on treasure castle lives. (p. 95)

\section{Marriage as a Negative Phenomenon: Problems after Marriage}

Marriage was not always positive and some had their negative attitudes towards it as well. This is probably because marriage brought a huge responsibility and limitations for men. The patriarchal nature of the proverbs therefore results in a controversial observation of marriage. Zolfaghri (2010) provides us with interesting proverbs: "Marriage is easy but dear its revelry" (p. 1141), "Affliction is the wife; calamity the child; disaster follows disaster" (p. 1141), "To get a wife is not to get a name; to keep her for good brings fame" (p. 1141). In a psychological research, the agitating events were graded among the list of which marriage was in the middle of the ranking: "Since marriage is a positive event and needs a lot of adaptations on the part of the couples, it was considered very important and crucial, hence the conventional 50 points placing it in the middle" (Atkinson et al., 2009, p. 491). Some of the crucial things related to marriage are about the responsibilities of a marital life which appear in the following proverbs: "Your wife needs to be fed, she wants meat, she needs bread; you have none, sell yourself anon" (Zolfaghari, p. 1140), "To marry is to be wedded to sorrow; oceans are little to buy or to borrow" (p. 1143).

Wanting a wife, work and build a house right now

Some furniture, some servants, and a land to plough

Water the land and feed all your serving men

Spend on the house or on the guests again

The child will come crying for food

Logic and reason will not serve him good. (O’hadi, 1928, p. 90)

There are negative proverbs that show the problems in marriages as well; for instance, marriages are believed to limit the individuals: "The wife is the castle and the husband a captive in it" (Zolfaghari, p. 1140). Psychologists have also referred to the limitations that marriage brings about for people. One of these limitations is lack of personal freedom (Rice, 2009, p. 524). There are some other similar negative qualities postulated in the proverbs: "A woman is able to turn his man either to a gentleman or a scoundrel; an unwise wife makes her husband grow old" (Zolfaghari, 2010, p. 1140, 1142). "If the couples sleep on separate beds, they will fall apart one brick farther everyday" (Zolfaghari, 2010, p. 1143). This proverb shows that the husband and the wife must always preserve their emotional and loving connection so that in the course of time they do not cool down. Rice (2009) believes that marital frustration is due to the gradual loss of emotional unity, lessening of compassion, the increase in apathy and indifference, and estrangement; little by little, positive emotions are replaced by negative or neutral emotions (p. 546). When the separation happens, then the woman is rejected not only by the husband's family but also by the whole society: "A woman, rejected by his man, is rejected by the men of the clan; a 
woman endeared by her man, is endeared by the clan" (Zolfaghari, 2010, p. 1142). The existence of harmony and understanding between the couples makes them acceptable people in their society. Research has proved that the people who divorce are less accepted in their society, even in modern societies. As Rice notes, despite the liberal and democratic views today, divorce is taken as the sign of moral or ethical failure and is indicative of the husband's inefficacy, a feeling that directly originates from divorce. Some men are divorced from their society after they divorce their wives (p. 549). This is also true for women and they are regarded negatively after divorce especially in Iran.

There is a saying in Persian that goes: "A widower should remarry, and a divorced man should marry a dog" (Zolfaghari, 2010, p. 1142), or "Give a wife to a widower, see a divorced man never" (p. 1142). These proverbs indicate that one cannot trust a man who has divorced his wife, and women have been warned against marrying such a man. Nonetheless, they find someone to marry again but the fear is always there for both sides. The study on the divorce shows that the people who had divorced once or more and remarried, their marriage was twice as much in danger as that of those who married for the first time. Many middle-age people who divorce their wives or husbands are those who had a failing marriage before (Burke, 2010, p. 304).

One of the main subjects in the proverbs is the antagonism against women. For example, in two couplets from Saadi (1996), we learn about the opinion of two men who feel helpless because of their wives; one prays that nobody ever has a bad wife and the other curses all women and believes that the world without women would be the best and wishes that it becomes so:

Excellent words I received from two men

Who were totally tired of their women

One said I wish bad wives were gone

Th' other desired of women none. (1998, 1.3143-44)

This example shows two men with similar problem. As we have shown, the bewilderment and agitation are due to the failure to come into harmony with the marital life and its responsibilities, the failure whose causes are absent in these lines from Saadi. Since one of the main conditions for an expression to become a proverb is its widespread use by the public, it must be the dominant idea of the ancients to see women as the cause of their problems. However, there is a general truth in these lines which finds its way into the contemporary time as well, that is, some men in our time still have the same outlook and many of the familial crises originate from a similar belief, the belief that women are evil and the cause of the existing problems in the world. About ninety percent of the married couples complain about the existing problems between them (see Barron, p. 485). The problems have always been there and have been treated differently by different people at different times. The proverbs show that these problems were treated with denial or they were not taken very seriously: "The couples are mad at each other in the evening, and they are friendly again in the morning," "The couples hit one another like the plates," "The couples are two hot and cold frying pans" (Zolfaghari, 2010, p. 1143).

\section{Conclusion}

Persian proverbs play an important role in women studies. These proverbs are replete with varied ideologies for or against women. Despite being very effective, they have been almost ignored by the scholars. What we attempted in this study besides emphasizing on the influence of these proverbs, was to demonstrate the problems that the study of women in the Persian proverbs cause for the scholars and reveal the contradictions which make any judgment impossible. We hope that the study of the existing contradictions or oppositions in the portrayal of women in Persian proverbs will provide objective results to help other scholars further the studies on and about women in similar areas.

\section{References}

Anvari, M. I. M. (2010). Collected Poetry. Tehran: Negah.

Atkinson, R. et al. (2009). Hilgard Introduction to Psychology. (Trans.) Mohammad Taghi Baraheni et al. Tehran: Roshd.

Barron, R. et al. (2011). Sociological Psychology. (Trans.) Yousef Karami. Tehran: Ravan.

Borhani Shahrestani, M. A. (2006). Women Mirrored in the Proverbs. Meshhad: Arman Kherad.

Burke, L. (2010). Psychology Growth. (Trans.) Yahya Seyed Mohammadi. Tehran: Arasbaran.

Cohen, S. B. (2005). Male Brain vs. Female Brain II: What is an "Extreme Male Brain"? What is an "Extreme Female Brain"? (Trans.) Gisou Nasseri. Tehran: Pol. 
Davari, P. (2005). Another Look at a Woman's Status in Persian Literature; Pondering on Nizami's and Ferdowsi's Narration of the Story of Khosro and Shirin. The Journal of Researches and Studies of the Faculty of Literature and Humanities of Ispahan University, 41, 227-308.

Dehkhoda, A. (2011). Amsal and Hikam. Tehran: Parmis.

Durant, W. (2010). The Pleasures of Philosophy. (Trans.) Abbas Zaryab Khouyi. Tehran: Elmi-Farhangi.

Ferdowsi, A. (1997). Shahname. Tehran: Ghatre.

Golparvar, M. (2006). The Difference between Men and Women in Terms of Their Judgment about the Just World and Their Interest in Money and Finance. The Journal of Educational Sciences and Psychology of Sistan and Balouchestan University, 45, 45-62.

Gorgani, F. A. (1970). Weis and Ramin. Corrected by Magali Tudela et al. Tehran: Bonyad and Farhang Publication.

Gray, J. (2012). Men are From Mars, Women are From Venus. Trans. Behzad Rahmati. Tehran: Talash.

Keinia, M. (1975). The Influential Psychological factors in family Crisis. The Journal of Maktab Imam, 74, $22-29$.

Mardiha, S. M. (1984). Feminism and Romanticism. The Journal of Social Sciences; Woman in Politics and Development, 12, 5-28.

Mohammadpour, A. et al. (2012). An Elaborate Study of Women in Kurdish Proverbs. Women in Culture and Art, 3, 65-83.

Movahhed, M. et al. (2012). "A Sociological Study of Women in the Proverbs of Lamerd in Fars Province" in Woman in Culture and Art. 2: 101-120.

Nasser Khosrow, A. M. (1997). Collected Poetry. Corrected by Jaafar Shoar and Kamel Ahmadnejad. Tehran: Payam Emrouz.

Nizami, E. I. Y. (1999). The Complete Works of Hakim Nizami Ganjavi. Corrected by Vahid Dastgerdi. Tehran: Behzad.

O'hadi Maraghee, O. (1908). Jam-e-jam. Tehran: Ferdowsi. The Eighth year Armaghan Supplement.

Rice, P. (1999). Human Development: a Life-Span Approach. (Trans.) Mahshid Foroughan. Tehran: Arjmand.

Saadi, M. (1995). Golestan. Corrected and Annotated by Gholam Hossein Yousefi. Tehran: Kharazmi.

Saadi, M. (1996). Boostan. Corrected and Annotated by Gholam Hossein Yousefi. Tehran: Kharazmi.

Sajjadi, A. M. et al. (2008). Woman and the Fall; How False Beliefs about Women Flourished in Some Persian Literary Texts. The Research Journal of Humanities, 57, 161-186.

Sanayee, M. I. A. (2011). Collected Poetry. Tehran: Negah.

Sattari, J. (2009). The Portrait of a Woman in Iranian Culture. Tehran: Markaz.

The Oxford English Dictionary. (2009). [computer software]. Oxford: Oxford university Press.

Walter O. Simmons, Rosemarie Emanuele (2007). Male-Female Giving Differentials: Are Women More Altruistic? Journal of Economic Studies, 34, 534-555. http://dx.doi.org/10.1108/01443580710830989

Zolfaghari, H. (2010). The Encyclopedia of Persian Proverbs. Tehran: Moein.

\section{Note}

Note 1. They rhyme in Persian too; نزن (zan) means a woman and بزن (bezan), with an addition of the letter the beginning of the word, means to beat.

\section{Copyrights}

Copyright for this article is retained by the author(s), with first publication rights granted to the journal.

This is an open-access article distributed under the terms and conditions of the Creative Commons Attribution license (http://creativecommons.org/licenses/by/3.0/). 